\title{
Tin oxide meshes consisting of nanoribbons prepared through an intermediate phase in an aqueous solution
}

Hiroaki Uchiyama and Hiroaki Imai*

E-mail address: hiroaki@applc.keio.ac.jp (H. imai).
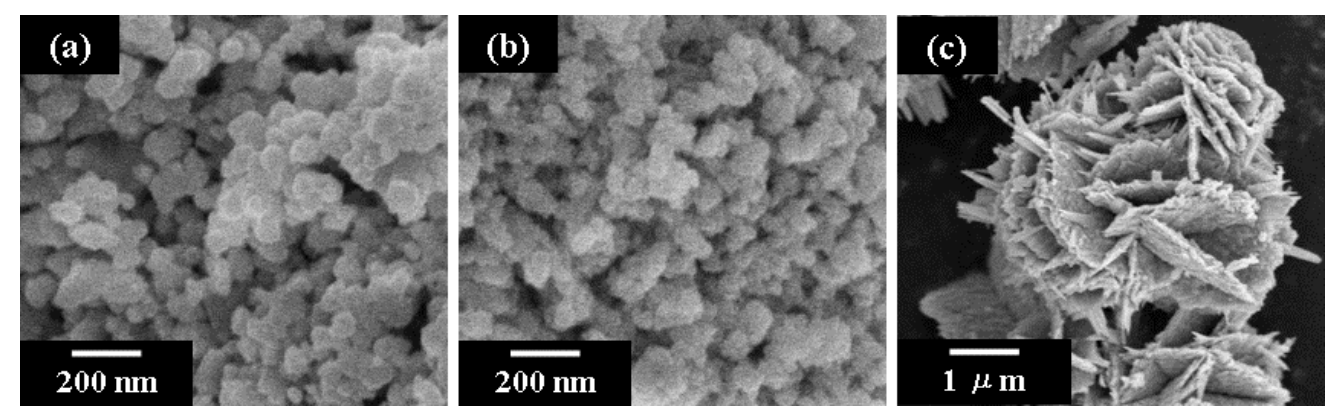

Figure S1. SEM images of white sol prepared without organic additives (a), with citric acid (b) and an irregularly grown $\mathrm{SnO}$ particle (c).
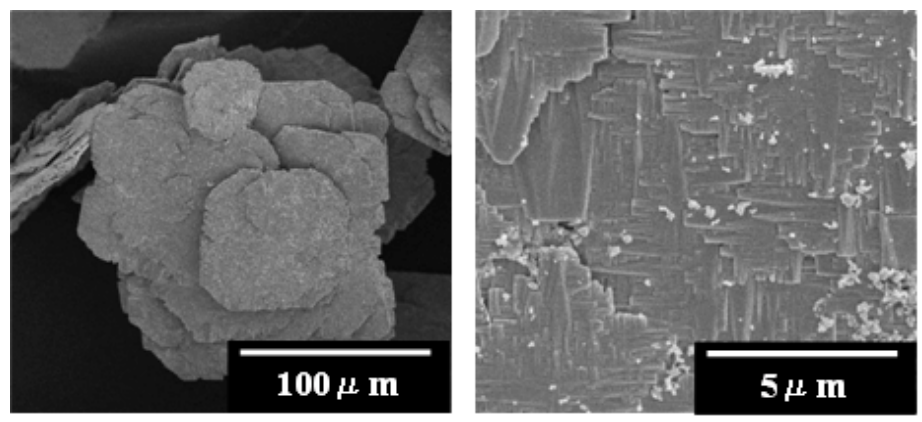

Figure S2. SEM images of crystalline SnO prepared with $[\mathrm{SnF} 2]=300 \mathrm{mM}$. 


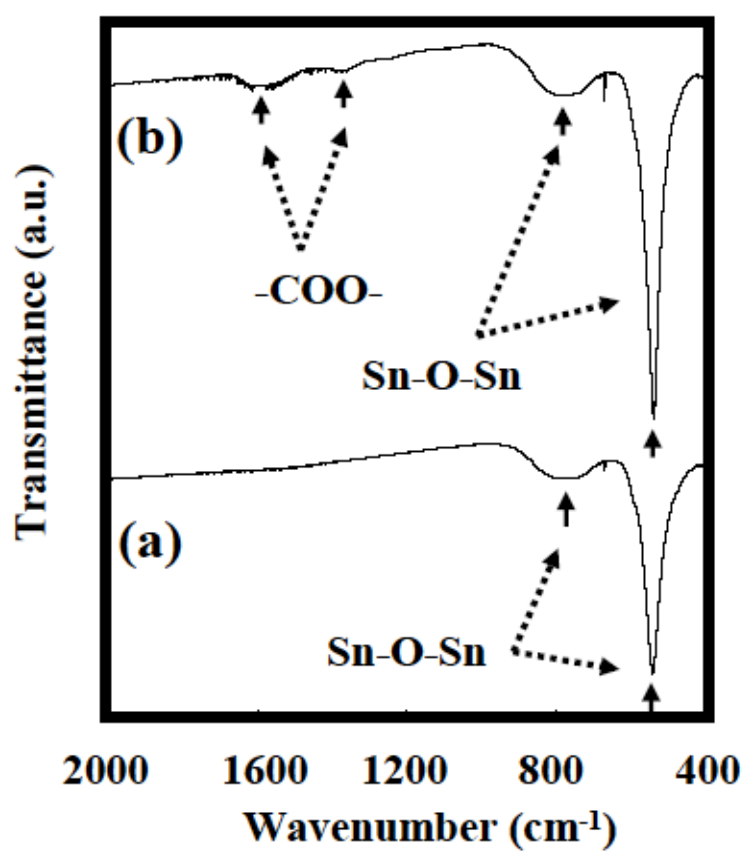

Figure S3. FT-IR absorption spectra of $\mathrm{Sn}_{6} \mathrm{O}_{4}(\mathrm{OH})_{4}$ prepared without (a) and with citric acid (b). 